\title{
Monetary value of informal caregiving in dementia from a societal perspective
}

\section{Pitkälä, Kaisu H.}

2020-10-01

Pitkälä , K H , Laakkonen , M-L , Kallio , E-L , Kautiainen , H , Raivio , M M , Tilvis , R S , Strandberg , T E \& Öhman , H 2020 , ' Monetary value of informal caregiving in dementia from a societal perspective ' , Age and Ageing , vol. 49 , afaa196 . https://doi.org/10.1093/ageing/afaa196

http://hdl.handle.net/10138/334800

https://doi.org/10.1093/ageing/afaa196

unspecified

acceptedVersion

Downloaded from Helda, University of Helsinki institutional repository.

This is an electronic reprint of the original article.

This reprint may differ from the original in pagination and typographic detail.

Please cite the original version. 
Monetary value of informal caregiving in dementia from a societal perspective

Pitkala KH ${ }^{1}$, Laakkonen ML ${ }^{1,2}$, Kallio EL ${ }^{1,3}$, Kautiainen $H^{1}$, Raivio MM ${ }^{1}$, Tilvis RS $^{4}$, Strandberg $\mathrm{TE}^{4,5}$, Ohman $\mathbf{H}^{1,5}$

${ }^{\mathbf{1}}$ University of Helsinki, Department of General Practice, Helsinki, Finland and Helsinki University Hospital, Unit of Primary Health Care, Helsinki, Finland

${ }^{2}$ Geriatric Clinic, Department of Social Services and Health Care, Laakso Hospital, Helsinki, Finland

${ }^{3}$ Clinical Neurosciences, Neuropsychology, University of Helsinki and Helsinki University Hospital, Helsinki, Finland

${ }^{4}$ University of Helsinki, Clinicum, Department of Geriatrics, Helsinki, Finland

${ }^{5}$ Helsinki University Hospital, Clinics of Internal Medicine and Geriatrics, Helsinki, Finland

Correspondence to:

Kaisu H Pitkala

$\mathrm{MD}, \mathrm{PhD}$, Professor

University of Helsinki, Department of General Practice and Primary Health Care

P.O. Box 20

FI-00014 University of Helsinki

Finland

Telephone: $+358-503385546$

E-mail: kaisu.pitkala@helsinki.fi

Acknowledgements: These studies were supported by the Social Insurance Institution of Finland, the Finnish Slot Machine Association, the Central Union for the Welfare of the Aged, the Sohlberg Foundation, and King Gustaf V and Queen Victoria's Foundation, the Finnish Medical Society, Helsinki University Hospital EVO Funding, the Health Center of the City of Helsinki, the Signe and Ane Gyllenberg's Foundation and the Finnish Brain Foundation. The funding organizations had no role in study design, data collection and analysis, decision to publish, or preparation of the manuscript. 


\begin{abstract}
Background and aim: Dementia is a condition which results in high cost of care, a significant proportion of which is the cost associated with informal care. In previous studies, informal caregiving has been challenging to assess due to difficulties in estimating true time spent on caregiving work and how to value caregivers' time. The aim of this study was to compare the costs of dementia among patients living alone and among those living with a caregiver to show the monetary value of informal caregiving from a societal perspective.
\end{abstract}

Methods: Data from our four dementia trials using the same measures were combined, allowing 604 participants to be included. Participants were followed up for two years or until death for their use of health and social services. Use of all services was retrieved from medical/social records. We also included the costs of lost productivity of those caregivers who were not retired.

Results: The total mean cost of services and lost productivity was $22068 €$ /person-year (pyrs). Participants living alone had a mean cost of $45156 € /$ pyrs, whereas those living with a spouse had a mean cost of $16416 €$ /pyrs (mean cost ratio $2.99,95 \%$ CI 2.64 to 3.39). Participants living alone and having < 15 MMSE points had higher costs than people with dementia in institutional care.

Key conclusions: Detailed data of service use and characteristics of people with dementia showed that from a societal perspective living alone is a very strong determinant of service use in dementia. Informal caregivers do invaluable work for society. 


\section{Introduction}

There is a large cost associated with the care of people with dementia (PWD) due to the extensive needs for personal care, long-term care and various health care services [1,2].

The yearly costs of patient care have varied greatly [3] depending on characteristics of the patients, country, how formal and informal costs have been taken into account and follow-up times [4].

Whereas a large proportion of cost studies have been dementia drug trials, the target population has mainly included community-dwelling people with mild-moderate dementia [5]. Of them, only a small proportion enters nursing homes, which is one of the main cost drivers in dementia [6].

Some studies present only direct costs including social care costs (home care, day care, nursing home) and medical care costs (hospitals, outpatient care, drug use) [6]. Several studies include also hours of informal care in their direct costs which are counted as either replacement costs (the value of equivalent service purchased from the market) or opportunity costs (the value of the caregiver's time in its best alternative use) [6,7]. However, quantification and costing of informal care are extremely challenging [5]. In many studies, the estimated time for caregiving has exceeded that of total time available because of multitasking [7] or difficulties in estimating the time spent on supervision [8].

Studies have also presented indirect costs which include costs of informal care as costs of lost productivity of working-aged individuals (either caregivers or PWD) [6]. In most studies, informal costs have comprised the largest proportion of total care $[5,7,8]$.

To sum up earlier studies have presented a wide range of estimates of costs of informal care using various approaches to evaluate the caregiving work. This study aims to compare the total costs of PWD living alone with respective PWD living with a caregiver. This enables us to also estimate the monetary value of work of those caregivers living with PWD. We use the detailed social and 
medical care costs from our previous four non-pharmacological trials following PWD for two years for their use of services. 


\section{Methods}

\section{Participants}

Data on participants from our four earlier dementia trials using the same measures were combined: (I) Case coordinator trial ( $\mathrm{N}=125)$ [9], (II) FINALEX exercise trial (N=210) [10], (III) Selfmanagement trial $(\mathrm{N}=134)$ [11] and (IV) FINCOG cognitive training trial $(\mathrm{N}=147)$ [12]. All trials received ethical permission from Helsinki University Hospital. Briefly, all trials had a nonpharmacological intervention to be tested among PWD I: case coordinator tailored services and giving support to dementia families for two years, II: exercise intervention supervised by a physiotherapist twice a week for one year either in the gym or at the participant's home, III: a group-based self-management group rehabilitation for people recently diagnosed with dementia and concurrently for their spouses, IV: supervised cognitive training twice a week for three months in a day care center for people with mild-moderate dementia. The four trials included a range of PWD from mild to severe stages, living alone or with a spouse or another caregiver. All participants in these studies were followed up prospectively for two years. Although some of these trials had positive effects on postponing institutional care [9] and improving physical or cognitive functioning $[10,11]$, all interventions were cost-neutral when the intervention and control arms were compared. Thus, they provide a dataset to explore costs of health and social services. The intervention costs are not taken into account in the present study.

\section{Characteristics}

All trials used the same measures. The demographics were recorded for both PWD and their possible caregivers. If the caregiver was not available for the person with dementia, the information was inquired from the participant's closest relative or from a home or day care nurse. Living alone or with a spouse or with another close person was retrieved from central registers. 
The participants with dementia were assessed with the Clinical Dementia Rating (CDR) scale [13] and the Mini Mental State Examination (MMSE) [14] for the severity of dementia. The item "personal care" in CDR was used to evaluate physical functioning [13]. All medical diagnoses and regularly used medications were retrieved from medical records. Charlson comorbidity index was constructed [15]. The use of antidementia medications was recorded (N06DA02 donepezil, N06DA03 rivastigmine, N06DA05 galantamine, N06DX01 memantine). In trials I and II, the caregiving burden was assessed with the Zarit burden interview, with 60 points or over considered as severe burden [16]. In trials III and IV, the caregivers were assessed with RAND-36 [17], and the item: "..for the past four weeks "Did you feel worn out?" and the responses "All the time" or "Most of the time" were considered to denote severe burden.

\section{Costs}

Participants were followed up prospectively for two years or until death regarding their use of health and social services. Service use was retrieved from medical/social records. Health care costs included the use of subacute rehabilitation and acute specialised hospitals, emergency department and ambulatory care visits, hospital-at-home visits, primary health care visits (general practitioner, nurse, physiotherapist, social worker) and home visits by doctors, dementia nurses or home care nurses. Social care included home care, day care, respite care and nursing home days. In Finland, all community care services and utilisation of hospitals are recorded in central registers and medical and social records, which were accessed after obtaining participants' consent. Service costs were determined at their mean unit costs according to the national cost registers in 2011 [18], with an appropriate correction for inflation rate. The costs of antidementia medications were retrieved from the Finnish drug database. All costs were calculated in Euros $(€)$ and transformed to 2019 rates.

The indirect costs were evaluated as costs of lost productivity of those of working age for both participants with dementia and caregivers who were younger than the average retirement age in 
Finland (men 61.6 years, women 60.9 years) [19]. The cost of lost productivity was valued as the average wage in Finland (men $19.21 € / \mathrm{h}$, women $16.45 € / \mathrm{h}$ ) [20], and we used the average ADL/IADL caregiving time (1.9 h/day) for people with dementia in previous studies [6].

We aimed to estimate the real value of the work of informal caregivers living with the person with dementia. Therefore, we excluded replacement costs and opportunity costs which are actually important monetary savings that informal caregivers' work confers to society. Our cost calculation is in line with the principles presented by Wimo et al. [6].

Costs are presented in our study as total costs and as the mean costs per person year.

\section{Statistical analyses}

Baseline characteristics between groups were compared using t-tests (for continuous variables) or Chi-square tests (for categorical variables). The bootstrap-type t-test was used when the theoretical distribution of the test statistics was unknown or in case of violation of the assumptions (e.g. nonnormality). The visits to professionals of health and social care were analysed by using Poisson's model and reported as mean (SE) days or visits and incidence rate ratios (IRRs) with 95\% confidence intervals (CIs). Cost analyses were performed using bootstrap-type generalised linear models with appropriate distribution and link function (10000 replications). The variance function was selected based on the Park test and Akaike's information criterion. The models included age and sex as covariates. The normality of variables was evaluated graphically and by using the Shapiro-Wilk W test. Stata 16.0 (StataCorp LP; College Station, Texas, USA) statistical package was used for the analysis. 


\section{Results}

The participants living alone were younger, more often females and less educated than those living with a caregiver. They had a milder stage of dementia and needed less assistance in their personal care than those living with a caregiver. They used more often memantine and less often cholinesterase inhibitors (ChEIs) than those living with a caregiver. (Table 1).

Older age, female sex and severity of dementia increased total costs of care (data not shown). Living alone was a very strong determinant of costs of services. Those living alone used significantly more home care services, day care, subacute hospital care and institutional care than those living with a caregiver. Those living alone used less respite care, specialised care, emergency care and various primary care services, except for family physician's home visits. The lost productivity costs were higher in the group of PWD living alone than among those living with a caregiver (3883€/pyrs vs. $193 € /$ pyrs). Those living alone had a caregiver of working age, whereas most of the caregivers living with a person with dementia were aged spouses (Table 2).

The mean costs of services were $49156 € /$ pyrs among those living alone, whereas the respective figure was $16416 €$ for those living with a caregiver (mean cost ratio 2.99 ; 95\%CI 2.64 to 3.39 ). Adjusting for age and sex (mean cost ratio 2.95; 95\%CI 2.55 to 3.35) did not change this difference between the costs. We made further adjustments for age, sex and CDR, or for age, sex and Charlson comorbidity index, but these yielded similar results (data not shown).

The severity of dementia was also a strong determinant in the use of services. The costs increased linearly with severity of dementia (Figure 1). At a moderate stage of severity (CDR2 or MMSE $<15$ points), the costs of PWD living alone exceeded the corresponding costs of those living in permanent institutional care (mean costs in Finland 51465€/year). There were no PWD living alone at home and having <10 MMSE points, whereas many caregivers lived with a person with dementia 
with very low MMSE points. Participants living with a spouse had lower costs than PWD in institutional care even when having zero MMSE points. 


\section{Discussion}

Living alone is a strong determinant of costs of dementia. The mean costs for services together with those of lost productivity among people with dementia living alone is $49156 € /$ pyrs, whereas the respective figure among those living with a caregiver is $16416 € /$ pyrs. Even after various adjustments, the costs are nearly three times higher among those living alone than among those living with a caregiver. The work that caregivers living with PWD do has a high monetary value, generating considerable savings for society.

Strengths of this study include detailed data and validated measures on the demographics, functioning, cognition, caregiver status and services used. Finnish medical and social registers include very detailed and complete data on use of services of PWD. We also included lost productivity costs to show the true value of caregiving from a societal perspective. The follow-up of two years is exceptionally long and allows us to evaluate the true course of dementia, including those entering permanent institutional care.

Limitations of the study include the data being retrieved from randomised controlled trials. Trials have exclusion criteria and there is a bias towards recruiting younger and healthier participants than in the normal service system. However, these four trials testing non-pharmacological interventions are much more pragmatic than many previous antidementia drug trials, which have been a major source for investigating costs of dementia $[5,8,21]$. Our participants were older with more comorbidities than participants in earlier studies [1,5,7,8,21-25], which also included a wide range of people having very mild to very severe dementia. However, people participating in our trials have less severe dementia and use more often antidementia medications than those in large epidemiological studies [1,25-27]. Furthermore, the caregivers in our study are younger and better educated than those in Finnish epidemiological study [26]. In addition, the health and social care systems as well as the local policies vary from country to country and the service system has also 
developed in Finland over the years from our first study. This makes the comparison to other contexts challenging although the components of services are similar to those in the Swedish system [6].

In line with a Swedish study, people living alone used less antidementia medications than those living with a caregiver [28]. In Finland memantine is recommended at moderate-severe stage of dementia. It seems that CHEIs are stopped and memantine started at earlier stage for those people with dementia living alone than those living with a caregiver.

Another limitation is that the caregiving time of $1.9 \mathrm{~h} /$ day is a coarse estimate of the true caregiving time based on a previous study [6]. In our first trial "Caregiving as collaboration", we found that it is impossible for caregivers to evaluate how much time they spend on caregiving and how much on regular housework. This has also been noted in an earlier study [6]. However, if the true caregiving time is higher - as our participants had more severe dementia than in previous studies - the difference between the costs of those living alone compared with those living with a caregiver would be even higher. This is due to the fact that those living alone had more caregivers of working age, thus indicating more lost productivity. Therefore, societal savings from caregiving might be an underestimation of the true value.

Our estimate of yearly costs of care and services for dementia (22068 €/pyrs) is comparable to figures presented elsewhere $[2,3,4,21]$. The unit costs of services used in the present study are similar to those presented in Sweden [6]. However, compared with earlier studies medication costs today are very low due to the inexpensive generic antidementia medications.

The difference in costs between those living with a caregiver (16416€/pyrs) and those living alone (46156 €/pyrs) was quite large. To our knowledge, there are no earlier studies comparing these groups of PWD. It has been noted before, however, that a caregiver's closeness to the person with dementia reduces total care costs [29]. Those living alone use an exceptional amount of home care 
services, day care and subacute hospitals. They are also admitted earlier to nursing homes, resulting in higher use of institutional care. Our study clearly shows that caregivers' work has a very high monetary value to societies. The proportion of informal care costs of the total care costs has varied greatly $(8-78 \%)$ in previous studies [3].

The care for PWD has shifted from society to informal caregiving. The relative number of nursing home beds is decreasing in many European countries [6,30]. It has been argued that care at home is cheaper than in a nursing home. This is, however, only true among those people with dementia who live with their caregiver. Our study suggests that care for a person with dementia living alone at home may be more expensive than care for a person with dementia in a nursing home. This applies when MMSE points are lower than 15, ie at a moderate stage of dementia. This should be taken into account when planning services for PWD.

\section{Conclusions}

Detailed data on service use and characteristics of PWD showed that informal caregivers do invaluable work for society. From a societal perspective, living alone is a very strong determinant of costs in dementia. The costs of living alone exceed those of permanent institutional care already at a moderate stage of dementia. In contrast, the costs of PWD living with a caregiver are far below those of permanent institutional care even at a very severe stage of dementia. 


\section{References}

1. Gustavsson A, Brinck P, Bergvall N, et al. Predictors of costs of care in Alzheimer's disease: a multinational sample of 1222 patients. Alzheimers Dement 2011a; 7: 318-27.

2. Wittenberg R, Hu B, Jagger C, et al. Projections of care for older people with dementia in England: 2015 to 2040. Age Ageing 2020; 49: 264-9.

3. Jönsson L, Wimo A. The cost of dementia in Europe. A review of evidence, and methodological considerations. Pharmacoeconomics 2009; 27: 391-403.

4. Mauskopf J, Racketa J, Sherrill E. Alzheimer's disease: the strength of association of costs with different measures of disease severity. J Nutr Health Aging 2010; 14: 655-63.

5. Quentin W, Riedel-Heller SG, Luppa M, Rudolph A, König HH. Cost-of-illness studies of dementia: a systematic review focusing on stage dependency of costs. Acta Psychiatr Scand 2010; 121: 243-59.

6. Wimo A, Jönsson L, Fratiglioni L, et al. The societal costs of dementia in Sweden 2012 relevance and methodological challenges in valuing informal care. Alzheimers Res Ther 2016; 8: 59.

7. Schwarzkopf L, Menn P, Kunz S, et al. Costs of care for dementia patients in community setting: an analysis for mild and moderate disease stage. Value Health 2011; 14: 827-35.

8. Gustavsson A, Cattelin F, Jönsson L. Costs of care in a mild-to-moderate Alzheimer clinical trial sample: key resources and their determinants. Alzheimers Dement 2011b; 7: 466-73.

9. Eloniemi-Sulkava U, Saarenheimo M, Kautiainen H, et al. Effectiveness of supportive model for dementia families. A randomized, controlled trial. J Am Geriatr Soc 2009; 57: 2200-8.

10. Pitkälä KH, Pöysti MM, Laakkonen ML, et al. Effects of the Finnish Alzheimer disease exercise trial (FINALEX): a randomized controlled trial. JAMA Intern Med 2013; 173: 894-901.

11. Laakkonen ML, Kautiainen H, Savikko N, et al. Effects of self-management intervention on participants with dementia and their spousal caregivers. J Am Geriatr Soc 2016; 64: 752-60.

12. Kallio EL, Öhman H, Hietanen M, et al. Effects of Cognitive Training on Cognition and Quality of Life of Older Persons with Dementia. J Am Geriatr Soc 2018; 66: 664-670.

13. Hughes CP, Berg L, Danziger WL, Coben LA, Martin RL. A new clinical scale for the staging of dementia. Br J Psychiatry 1982; 140: 566-72.

14. Folstein MF, Folstein SE, McHugh PR. "Mini-mental state". A practical method for grading the cognitive state of patients for the clinician. J Psychiatr Res 1975; 12: 189-198.

15. Charlson ME, Pompei P, Ales KL, MacKenzie CR. A new method of classifying prognostic comorbidity in longitudinal studies: development and validation. J Chronic Dis 1987;40:373383.

16. Stagg B, Larner AJ. Zarit Burden Interview: pragmatic study in a dedicated cognitive function clinic. Progress Neurology Psychiatr 2015; 19(4):2 3-7.

17. Hays RD, Morales LS. The RAND-36 measure of health-related quality of life. Ann Med 2001; 33: 350-7.

18. Kapiainen S, Vaisanen A, Haula T. The unit costs of health and social care in Finland in 2011. In Finnish. The Finnish Institute for Health and Welfare. Report 3/2014. Juvenes Print . Suomen Yliopistopaino. Tampere 2014. 
19. Kannisto J. Effective retirement age in the Finnish earnings-related pension scheme. Statistics from the Finnish centre for pensions 3/2019. Finnish Centre for Pensions. In:

https://www.etk.fi/wp-content/uploads/effective-retirement-age-in-the-finnish-earnings-relatedpension-scheme-in-2018.pdf Accessed 24.2.2020

20. Statistics Finland. In http://pxnet2.stat.fi/PXWeb/pxweb/fi/StatFin/StatFin__pal_pra/statfin_pra_pxt_128s.px/table/ta bleViewLayout1/ Accessed 24.2.2020

21. Schaller S, Mauskopf J, Kriza C, Wahlster P, Kolominsky-Rabas PL. The main cost drivers in dementia: a systematic review. Int J Geriatr Psychiatry 2015; 30: 111-29.

22. Jönsson L, Eriksdotter Jönhagen M, Kilander L, et al. Determinants of costs of care for patients with Alzheimer's disease. Int J Geriatr Psychiatry 2006; 21: 449-59.

23. Jones RW, Lebrec J, Kahle-Wrobleski K, et al. Disease Progression in Mild Dementia due to Alzheimer Disease in an 18-Month Observational Study (GERAS): The Impact on Costs and Caregiver Outcomes. Dement Geriatr Cogn Dis Extra 2017; 7: 87-100.

24. Reese JP, Hessmann P, Seeberg G, et al. Cost and care of patients with Alzheimer's disease: clinical predictors in German health care settings. J Alzheimers Dis 2011; 27: 723-36.

25. Åkerborg Ö, Lang A, Wimo A, et al. Costs of dementia and its correlation with dependence. J Aging Health 2016; 28: 1448-64.

26. Raivio M, Maki-Petaja-Leinonen, Laakkonen ML; Pitkala K. Prevalence of the use of legal guardians or financial authorizations and the caregivers' need to discuss with a doctor about legal and financial competency among Finnish patients with Alzheimer's disease. J Med Ethics 2008; 34: 882-6.

27. Henderson C, Knapp M, Nelis SM et al. Use and costs of services and unpaid care for people with mild-to-moderate dementia: Baseline results from the IDEAL cohort study.

28. Alzheimers Dement (N Y). 2019; 5: 685-96.Cermakova P, Nelson M, Secnik J et al. Living alone with Alzheimer's disease: data from SveDem, the Swedish Dementia Registry. J Alzheimer Dis 2017; 58: 1265-72.

29. Rattinger GB, Fauth EB, Behrens S, et al. Closer caregiver and care-recipient relationships predict lower informal costs of dementia care: The Cache County Dementia Progression Study. Alzheimers Dement 2016;12:917-24.

30. Verbeek H, Meyer G, Leino-Kilpi H, et al. RightTimePlaceCare Consortium. A European study investigating patterns of transition from home care towards institutional dementia care: the protocol of a RightTimePlaceCare study. BMC Public Health 2012;12:68. 
Table 1. Characteristics of participants according to their living status.

\begin{tabular}{|c|c|c|c|}
\hline & $\begin{array}{l}\text { Living alone } \\
\qquad(\mathrm{N}=106)\end{array}$ & $\begin{array}{l}\text { Living with } \\
\text { caregiver } \\
(\mathrm{N}=508)\end{array}$ & $\mathrm{P}$ value \\
\hline Age, mean (SD) & $83(5)$ & $78(6)$ & $<0.001$ \\
\hline Women, n (\%) & $87(82)$ & $195(38)$ & $<0.001$ \\
\hline $\begin{array}{l}\text { Education } \\
<8 \text { years } \\
8-12 \text { years } \\
>12 \text { years }\end{array}$ & $\begin{array}{l}55(52) \\
23(22) \\
28(26)\end{array}$ & $\begin{array}{l}171(34) \\
132(26) \\
205(40)\end{array}$ & 0.002 \\
\hline $\begin{array}{l}\text { CDR, "personal care" } \\
\text { Fully capable of self-care } \\
\text { Needs prompting } \\
\text { Requires assistance in personal care } \\
\text { Requires much help in personal care }\end{array}$ & $\begin{array}{c}24(23) \\
36(34) \\
43(41) \\
3(3)\end{array}$ & $\begin{array}{l}109(22) \\
172(34) \\
157(31) \\
70(14)\end{array}$ & 0.020 \\
\hline Charlson comorbidity index, mean (SD) & $2.7(1.6)$ & $2.3(1.7)$ & 0.012 \\
\hline MMSE, mean (SD) & $20.6(3.8)$ & $17.9(6.5)$ & $<0.001$ \\
\hline Number of medications, mean (SD) & $8.4(3.1)$ & $6.3(3.2)$ & $<0.001$ \\
\hline $\begin{array}{c}\text { Antidementia medication, n (\%) } \\
\text { ChEI, n (\%) } \\
\text { Memantine, n (\%) }\end{array}$ & $\begin{array}{l}70(66) \\
50(47)\end{array}$ & $\begin{array}{l}417(82) \\
157(31)\end{array}$ & $\begin{array}{l}<0.001 \\
0.001\end{array}$ \\
\hline $\begin{array}{l}\text { CDR, } \mathrm{n}(\%) \\
\\
0.5 \text { very mild } \\
1 \text { mild } \\
2 \text { moderate } \\
3 \text { severe }\end{array}$ & $\begin{array}{c}11(10) \\
58(55) \\
37(35) \\
0(. .) \\
\end{array}$ & $\begin{array}{c}44(9) \\
177(35) \\
224(44) \\
63(12)\end{array}$ & $<0.001$ \\
\hline & $\begin{array}{l}\text { Caregiver not } \\
\text { living with } \\
\text { patient } \\
(\mathrm{N}=88)\end{array}$ & $\begin{array}{l}\text { Caregiver living } \\
\text { with patient } \\
\quad(\mathrm{N}=508)\end{array}$ & \\
\hline Caregivers' mean age (SD) & $60(11)$ & $76(7)$ & $<0.001$ \\
\hline Caregivers' sex: female, $(\%)$ & $60(68)$ & $314(62)$ & 0.27 \\
\hline Caregiver severely burdened $^{1}(\%)$ & $12(11)$ & $49(10)$ & 0.60 \\
\hline
\end{tabular}

$\mathrm{SD}=$ standard deviation; $\mathrm{CDR}=$ Clinical Dementia Rating scale (Hughes et al. 1982); Charlson (Charlson et al. 1987); MMSE=Mini-Mental State Examination (Folstein et al. 1975);

ChEI=Cholinesterase inhibitor; ${ }^{1}$ Severely burdened $=$ Zarit burden scale (Zarit et al. 1980) > 60 points or "Feels worn out all the time or most of the time for the past 4 weeks" (item from RAND36; Hays et al. 2001). 
Table 2. Number and costs of services used by participants with dementia and costs of antidementia medications and lost productivity costs of caregivers and participants with dementia below retirement age during the two-year follow-up.

\begin{tabular}{|c|c|c|c|c|c|c|}
\hline & $\begin{array}{l}\text { Living alone } \\
\qquad(\mathrm{N}=106)\end{array}$ & $\begin{array}{l}\text { Living with } \\
\text { caregiver } \\
(\mathrm{N}=508)\end{array}$ & IRR $(95 \% \mathrm{CI})$ & Unit cost, $€$ & $\begin{array}{l}\text { Living alone } \\
\quad(\mathrm{N}=106)\end{array}$ & $\begin{array}{l}\text { Living with } \\
\text { caregiver } \\
(\mathrm{N}=508)\end{array}$ \\
\hline Service & \multicolumn{2}{|c|}{ Mean number of used services (SD) } & & & \multicolumn{2}{|c|}{ Mean cost of services (SD) /pyrs } \\
\hline Direct costs & & & & & & \\
\hline \multicolumn{7}{|l|}{ Medical costs } \\
\hline Specialised hospital days & $1.03(0.26)$ & $2.96(0.44)$ & $0.35(0.20$ to 0.61$)$ & 792 & $874(224)$ & 2785 (392) \\
\hline Emergency department visits & $0.30(0.05)$ & $0.57(0.04)$ & $0.52(0.49$ to 0.65$)$ & 299 & $89(15)$ & $216(19)$ \\
\hline $\begin{array}{l}\text { Specialised ambulatory care } \\
\text { visits }\end{array}$ & $1.26(0.24)$ & $0.64(0.05)$ & 1.99 (1.33 to 2.96$)$ & 283 & $357(66)$ & $194(16)$ \\
\hline $\begin{array}{l}\text { Subacute or rehabilitation } \\
\text { hospital days }\end{array}$ & $21.53(3.24)$ & $7.73(0.90)$ & $2.48(1.73$ to 3.56$)$ & 252 & $5914(940)$ & $2682(285)$ \\
\hline Visits to GP & $0.93(0.13)$ & $2.03(0.08)$ & $0.46(0.34$ to 0.61$)$ & 119 & $110(15)$ & $246(10)$ \\
\hline GP home visits & $0.67(0.06)$ & $0.15(0.02)$ & $4.46(3.10$ to 6.40$)$ & 181 & $121(12)$ & $27(4)$ \\
\hline Nurse visits & $0.28(0.05)$ & $1.34(0.08)$ & $0.21(0.14$ to 0.31$)$ & 52 & $14(3)$ & $70(5)$ \\
\hline Physiotherapy visits & $0.33(0.07)$ & $1.53(0.21)$ & $0.22(0.13$ to 0.36$)$ & 124 & $41(9)$ & $187(26)$ \\
\hline Hospital at home days & $0.20(0.20)$ & $0.05(0.03)$ & $4.12(0.40$ to 42.33$)$ & 241 & $48(48)$ & $13(9)$ \\
\hline Antidementia medication costs & & & & $\begin{array}{l}\text { Donepezil } 0.07 € / \mathrm{d} \\
\text { Rivastigmine } 0.60 € / \mathrm{d} \\
\text { Galantamine } 0.72 € / \mathrm{d} \\
\text { Memantine } 0.08 € / \mathrm{d}\end{array}$ & $65(8)$ & $97(4)$ \\
\hline
\end{tabular}


Table 2. Continued..

\begin{tabular}{|c|c|c|c|c|c|c|}
\hline & $\begin{array}{l}\text { Living alone } \\
(\mathrm{N}=106)\end{array}$ & $\begin{array}{c}\text { Living with } \\
\text { caregiver } \\
(\mathrm{N}=508)\end{array}$ & IRR (95\% CI) & Unit cost, $€$ & $\begin{array}{l}\text { Living alone } \\
\quad(\mathrm{N}=106)\end{array}$ & $\begin{array}{c}\text { Living with } \\
\text { caregiver } \\
(\mathrm{N}=508)\end{array}$ \\
\hline \multicolumn{7}{|l|}{ Social care services } \\
\hline Home care services, visits & $423.68(28.81)$ & $26.29(4.12)$ & $\begin{array}{l}16.12 \text { (11.53 to } \\
22.52)\end{array}$ & 45 & $31021(1357)$ & $6588(410)$ \\
\hline Day care, days & $94.98(1.09)$ & $15.79(1.37)$ & $6.02(5.07$ to 7.14$)$ & 104 & $9850(124)$ & $1625(139)$ \\
\hline Respite care, days & $10.30(1.77)$ & $18.23(1.42)$ & 0.57 (0.39 to 0.82$)$ & 199 & $2014(344)$ & $3751(295)$ \\
\hline Social worker visits & $0.03(0.01)$ & $0.32(0.04)$ & $0.11(0.05$ to 0.25$)$ & 166 & $6(2)$ & $55(7)$ \\
\hline Nursing home days & $46.88(8.58)$ & $22.34(2.85)$ & $2.10(1.36$ to 3.25$)$ & 141 & $6614(1213)$ & $3064(387)$ \\
\hline \multicolumn{7}{|l|}{ Indirect costs } \\
\hline Lost productivity costs $^{1}$ & & & & & $3883(359)$ & $193(52)$ \\
\hline Total costs & & & & & $49156(1763)$ & $16416(846)$ \\
\hline
\end{tabular}

${ }^{1}$ The cost of lost productivity was valued as the average wage in Finland (men 19.21€/h, women 16.45€/h) (Tilastokeskus 2019), and calculated for those below the average retirement age in Finland (men 61.6 years, women 60.9 years) (Kannisto 2019). The average ADL/IADL caregiving time (1.9 h/day) was used for them (Wimo et al. 2016). 

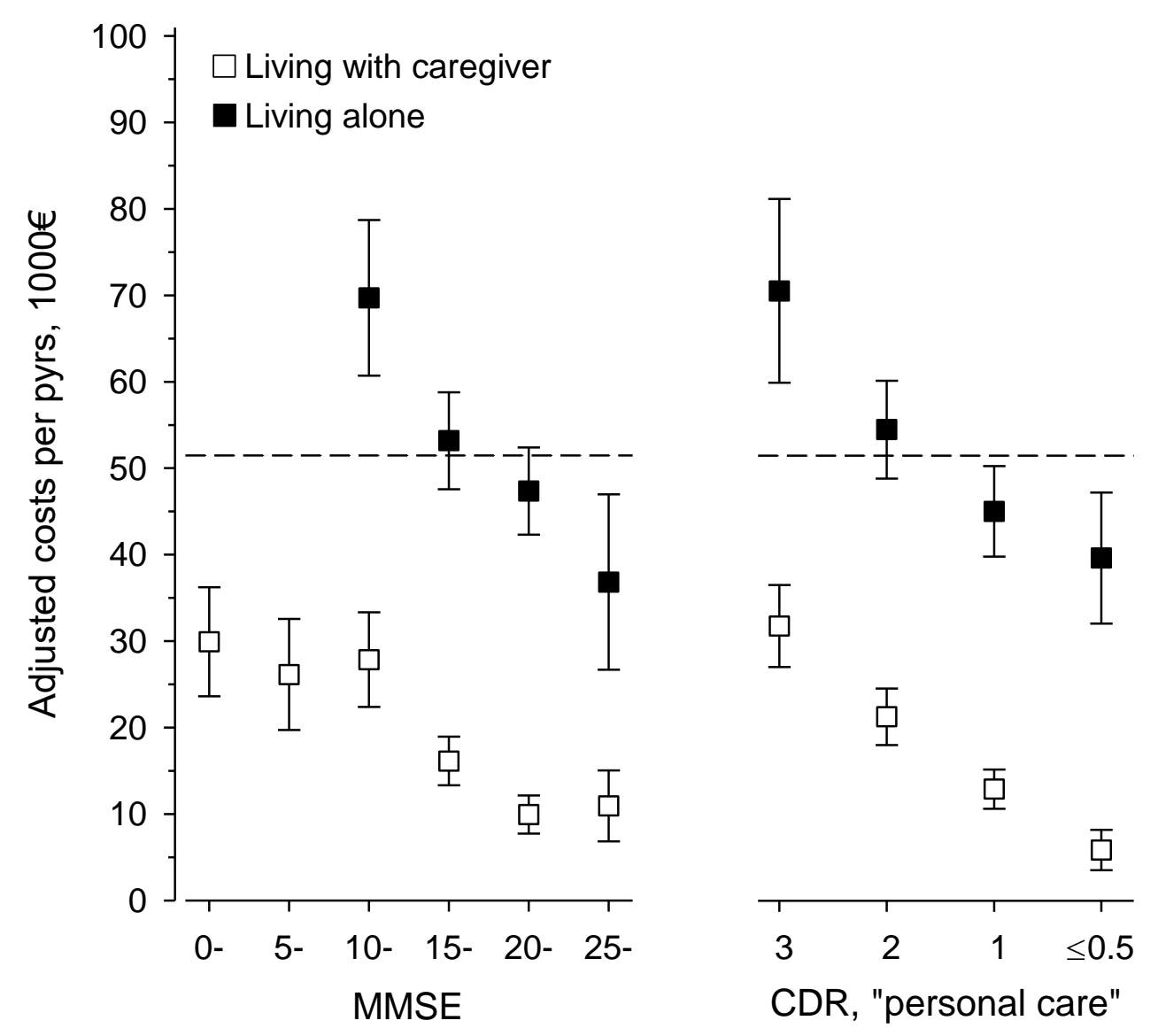

Figure 1. Age- and sex-adjusted costs of health and social care at various stages of dementia among those living alone versus those living with a caregiver. MMSE = Minimental State Examination (Folstein et al. 1975), CDR=Clinical Dementia Rating (Hughes et al. 1982), pyrs=person years. 